\title{
Factors contributing the outcome of Schizophrenia in developing and developed countries: A brief review
}

\author{
*Mahmuda Naheed ${ }^{1}$, Khondker Ayesha Akter ${ }^{1}$, Fatema Tabassum¹, Rumana Mawla², Mahmudur Rahman ${ }^{1}$ \\ ${ }^{1}$ Faculty of Health Science, Department of Pharmacy, Northern University Bangladesh, Dhaka-1215, Bangladesh \\ ${ }^{2}$ Faculty of Pharmacy, Dept. of Clinical Pharmacy and Pharmacology, University of Dhaka, Dhaka-1000, Bangladesh
}

\begin{abstract}
According to $\mathrm{WHO}$, schizophrenia is a severe form of mental illness affecting about 7 per thousand of the adult population, mostly in the age group 15-35 years. Though the incidence is low $(3-10,000)$, the prevalence is high due to chronicity. Schizophrenia is occurring in both developing and developed countries. The remission rate is higher in developing countries compared to the developed ones. There are some compelling factors that may influence the outcome of schizophrenia includes gender, employment, marital status, family support, illness myths, family burden, duration of untreated psychosis etc. In this review we have discussed the epidemiology, pathophysiology, diagnosis, treatment and finally the factors that influence the outcome of schizophrenia in developing and developed countries.
\end{abstract}

Key Words: Schizophrenia, outcome, developing countries, antipsychotic agents.

\section{INTRODUCTION}

Schizophrenia is a heterogeneous syndrome characterized by perturbations of language, perception, thinking, social activity, affect, and volition. There are no pathognomonic features. The syndrome commonly begins in late adolescence, has an insidious (and less commonly acute) onset, and, classically, a poor outcome, progressing from social withdrawal and perceptual distortions to a state of chronic delusions and hallucinations (Harrison et al., 2005). In this article we reviewed the factors that influence the outcome of schizophrenia in developing and developed countries.

\section{EPIDEMIOLOGY AND PATHOPHYSIOLOGY}

Epidemiologic surveys identify several risk factors for schizophrenia including genetic susceptibility, early developmental insults, winter birth, and increasing parental age. Genetic factors are involved in at least a subset of individuals who develop schizophrenia. Schizophrenia is observed in near about

\footnotetext{
*Corresponding Author:

Mahmuda Naheed, Senior Lecturer

Faculty of Health Science, Department of Pharmacy

Northern University Bangladesh, Dhaka, Bangladesh

E-mail: naheed2015@gmail.com

Contact No.: +8801671079884
}

$6.6 \%$ of all first-degree relatives of an affected proband. If both parents are affected, the risk for offspring is $40 \%$. The concordance rate for monozygotic twins is $50 \%$, compared to $10 \%$ for dizygotic twins. Schizophrenia-prone families are also at risk for other psychiatric disorders (Harrison et al., 2005).

Schizophrenia is also associated with gestational and perinatal complications, including $\mathrm{Rh}$ factor incompatibility, fetal hypoxia, and prenatal exposure to influenza during the second trimester, and prenatal nutritional deficiency. Studies of monozygotic twins discordant for schizophrenia have reported neuroanatomic differences between affected and unaffected siblings, supporting a "twostrike" etiology involving both genetic susceptibility and an environmental insult. The latter might involve localized hypoxia during critical stages of brain development.

\section{DIAGNOSIS AND TREATMENT}

Patients may present with positive symptoms (such as conceptual disorganization, delusions, or hallucinations) or negative symptoms (loss of function, anhedonia, decreased emotional expression, impaired concentration, and diminished social engagement) and must have at least two of these for 
Table 1. Typical and Novel antipsychotic agents ${ }^{1}$ (Harrison et al., 2005).

\begin{tabular}{|c|c|c|c|c|}
\hline \multicolumn{5}{|c|}{ TYPICAL ANTIPSYCHOTICS } \\
\hline & $\begin{array}{c}\text { Usual PO } \\
\text { Daily Dose, mg }\end{array}$ & Side Effects & Sedation & Comments \\
\hline $\begin{array}{l}\text { Low-potency } \\
\text { Chlorpromazine }\end{array}$ & $100-600$ & $\begin{array}{l}\text { Anticholinergic effects; } \\
\text { orthostasis; }\end{array}$ & +++ & $\begin{array}{l}\text { EPSEs usually not prominent; can cause } \\
\text { anticholinergic delirium in elderly patients }\end{array}$ \\
\hline Mid-potency & $2-15$ & Fewer anticholinergic side & & Well tolerated by most patients \\
\hline Trifluoperazine & & $\begin{array}{l}\text { effects; fewer EPSEs than with } \\
\text { higher potency agents }\end{array}$ & ++ & \\
\hline $\begin{array}{l}\text { High potency } \\
\text { Haloperidol }\end{array}$ & $0.5-10$ & $\begin{array}{l}\text { No anticholinergic side ef- } \\
\text { fects; EPSEs often prominent }\end{array}$ & $0 /+$ & $\begin{array}{l}\text { Often prescribed in doses that are too } \\
\text { high; long-acting injectable forms of halo- } \\
\text { peridol and fluphenazine available }\end{array}$ \\
\hline \multicolumn{5}{|c|}{ NOVEL ANTIPSYCHOTICS } \\
\hline \multicolumn{5}{|c|}{ Daily Dose, mg } \\
\hline Clozapine & $200-600$ & $\begin{array}{l}\text { Agranulocytosis }(1 \%) ; \\
\text { weight gain; seizures; } \\
\text { drooling; hyperthermia }\end{array}$ & ++ & Requires weekly WBC \\
\hline Risperidone & $2-6$ & Orthostasis & + & $\begin{array}{l}\text { Requires slow titration; EPSEs observed } \\
\text { with doses_6 mg qd }\end{array}$ \\
\hline Olanzapine & $10-20$ & Weight gain & ++ & Mild prolactin elevation \\
\hline Quetiapine & $350-700$ & $\begin{array}{l}\text { Sedation; weight gain; } \\
\text { anxiety }\end{array}$ & +++ & Bid dosing \\
\hline Ziprasidone & $40-60$ & Orthostatic hypotension & $+/++$ & Minimal weight gain; increases QT interval \\
\hline Aripiprazole & $10-30$ & Nausea, anxiety, insomnia & $0 /+$ & Mixed agonist/ antagonist \\
\hline
\end{tabular}

a 1-month period and continuous signs for at least 6 months to meet formal diagnostic criteria. "Negative" symptoms predominate in one third of the schizophrenic population and are associated with a poor long-term outcome and a poor response to drug treatment.

Antipsychotic agents are the cornerstone of acute and maintenance treatment of schizophrenia, and are effective in the treatment of hallucinations, delusions, and thought disorders, regardless of etiology. The antipsychotic agents are classified into two classes. They are typical antipsychotics and novel antipsychotic agents (Table 1).

\section{FACTORS AFFECTING OUTCOME OF SCHIZOPHRENIA}

According to world Health Organization, Schizophrenia affects about 24 million people worldwide. In developing countries around $90 \%$ of people with schizophrenia remain untreated. But the outcome of schizophrenia appears to be better in low and middle income countries (Isaac et al., 2007). There are several factors that may influence the outcome like employment, marital status, family support etc. Our aim of the study is to find out the factors that may affect the outcome of schizophrenia in developing in comparison with developed countries.

\section{Gender}

Sex differences in the risk of a particular disorder can yield important clues regarding its pathogenesis. The evidence for a sex difference in the risk of schizophrenia is inconclusive. No significant sex differences were reported in studies from developing countries (Aleman et al., 2003). That is schizophrenia is equally common in male and female. In a study carried out with fifty schizophrenic patients in Bangladesh it was found that $54 \%$ male and $46 \%$ female were suffering from schizophrenia (Ahammad et al., 2009). Which proves in case of schizophrenia gender difference is not a prime contributory factor in developing countries. Although sex difference is not a significant factor in schizophrenia, it has been ob- 
served that the clinical remission and recovery is higher in female rather than male (Carpiniello et al., 2012).

\section{Employment}

Physical and mental fitness plays a very important role in case of employment. These two are prerequisites in getting job in many countries. People with schizophrenia in low- and middle-income countries are more likely to be employed than their Western counterparts. In 1997 Srinivasan \& Thara found an annual rate of employment of $63-73 \%$ in the first 10 years of follow-up in a cohort of 90 people with first-episode schizophrenia (Srinivasan et al., 1997). Moreover, among untreated Indian people with schizophrenia almost one-third was employed (Padmavathi et al., 1998). Generally, high employment rates (up to $75 \%$ ) have been found in India (Thara et al., 2004). A similar trend is described among Chinese patients; nearly half were able to work after 5, 10 and 15 years of follow-up (Tsoi et al., 1991). These rates of employment are markedly higher than those in similar populations in high income countries (Mueser et al., 2001).

It has been mentioned earlier around 90\% schizophrenic patient remain untreated in developing countries whereas their remission appears to be better, this is probably due employment. When a schizophrenic patient involved in a job he comes in contact with social surroundings and routine work; which helps to lead a normal life. In low- and middle-income countries, social bonding is very strong and work place colleagues are very co-operative. Even study proves that workplace colleagues are found to be generally supportive in low- and middle income countries (Srinivasan et al., 2005). The employment rate in the UK over the past 20 years among people with schizophrenia ranges from 4 to $31 \%$; whereas most Western studies report a rate between 10 and 20\% (Marwaha et al., 2004).

From this discussion it is observed that in low- and middle-income countries a large population with schizophrenia remains untreated. Untreated patient engaged in job. In their service life they become a part of the society and get support from the surroundings to become a part of the society, It compel them to lead a normal life and help them in their remission.

\section{Marital status}

In low- and middle-income countries society plays a very important role in case of marriage. In these countries marriage considered as a social identity for a person. In developing countries marriage is an once-in-a-lifetime event and is associated with a high degree of social approval. The sociocultural factors determining marriage and its maintenance are vastly different from those in Western societies. Marital state can be considered an outcome measure, as its maintenance depends on stability and functioning of both partners. Schizophrenia manifests maximally at a marriageable age (i.e. around the 20s). Most studies from the West have reported low rates of marriage for people with schizophrenia (Nanko et al., 1993, Harrison et al., 2001). In contrast, a 10-year follow-up study from India found a high marital rate of $70 \%$ (Thara et al., 1996). So the marriage rate of schizophrenic patient in developing countries is much higher than that of developed countries. This is because in developing countries schizophrenic patients live with their partners and share their views and feelings. This mental support helps them to lead a normal life and also affect their outcome.

Patients, whose marriages have broken down, in addition to the stress of their mental illness, face hostility from family members and rejection by society. This can be a significant contributing factor to outcome in traditional societies (Thara et al., 2003).

\section{Support from family and society}

Family and social support plays vital role in the outcome of schizophrenia. Recent studies propose that supportive and favorable attitudes among family members and the community contribute to the improved outcomes (Kurihara et al., 2000, Kurihara et al., 2005). In low and middle incoming countries, majority of people stay in joint families. Schizophrenic patients from these families primarily stay at home as the numbers of family members are large. Since they stay in a family surrounding and get sufficient care from the members, their outcome accelerated in low and middle incoming countries. The mean time spent in hospital by people with schizophrenia is approximately a fifth in Bali compared with Tokyo (Kurihara et al., 2000). Studies from Asian countries showed that less than 10\% were hospitalized during follow-up, suggesting 
high levels of family involvement in patient care (Ganev et al., 1998). Migration, urbanization, changes in family structure and social support networks, plus the increase in economic insecurity and widening social inequalities which are evident in low- and middle-income countries will change the social support available for people with schizophrenia and influence their outcome (Patel et al., 2006).

\section{Illness myths}

A significant delay in seeking treatment for people with schizophrenia has been observed in low- and middle-income countries. The reason behind that may be ignorance, superstition and Misconceptions of illness. However, recent studies have shown that very few people still named supernatural factors alone as a cause of schizophrenia (Srinivasan et al., 2001). In a study of Indian patients supernatural cause was named by only $12 \%$ of families with a member with schizophrenia (Srinivasan et al., 2001).

\section{Family burden}

Burden of care is related to the different sociocultural factors of a country. As in low- and middleincome countries the majority of patients stay with their caregivers. So the burden is somewhat higher in low- and middle-income countries compared to the western countries. In a study it has been found that, there are six areas of burden these are financial, family routine, leisure, interaction, effect on physical health and effect on mental health (Pai et al., 1982) .In addition, inability to care for others, unpredictable behavior of the patient and dissatisfaction with the help from health care professional also be considered as burden. Some family members leave their ill relatives in psychiatric hospital for long time but in that case the outcome follows negative trend. Study shows that caregiver burden decreases with a reduction in the patient's symptoms and improving drug adherence. Reduction of family burden is associated with better outcome and social functioning (Pai et al., 1982).

\section{Duration of untreated psychosis (DUP)}

Studies from the West have shown that the duration of untreated psychosis (DUP) is associated with poorer outcome; with the relationship being strongest in the initial months of psychosis (Drake et al., 2000).This is particularly relevant in low- and middle-income (LAMI) countries where a significant number of patients come late for treatment. Reasons for this include lack of awareness, a strong belief in magical or religious causes, poor accessibility to healthcare systems and lack of community care (Isaac et al., 1981, Padmavathi et al., 1998).

Non-adherence to prescribed antipsychotic medications places patients with schizophrenia at a greatly increased risk of illness exacerbation and rehospitalization (Lacro et al., 2002). There appears to be an inverse relationship between income and DUP in LAMI countries. The cost of treatment is an impediment to care and subsidized antipsychotic medication would improve the access to treatment and the outcome of psychotic illness in LAMI countries. The average mean DUP in a study from LAMI countries was 125.0 weeks compared with 63.4 weeks in studies from high-income countries (Large et al., 2008).

\section{CONCLUSION}

It has been found that supportive and favorable attitudes among family members and the community contribute to the improved outcomes. Moreover workplace colleagues are found to be generally supportive in low and middle-income countries. These factors also affect the outcome as well as the remission rate. Clinical outcomes of schizophrenia seem to be worse in Europe compared with other regions. In a 3-year follow-up study it was found that the remission rate is $60.1 \%$ in North Europe and 84.4\% in East Asia (Haro et al., 2011). In the majority of the studies we reviewed, did not use standardized and culturally appropriate instruments. Longitudinal studies using parameters such as neurocognitive function and quality of life are almost non-existent. Further studies regarding better outcome needs to be examined through prospective studies.

\section{REFERENCES}

Ahammad, J.U., Rahman, M.H., Islam, M.A., Rahman, M.S., Rabbani, M.G. (2009). Demographic features and common presentations of schizophrenia. JAFMC Bangladesh. 1: 2933.

Aleman, A., Kahnm, R.S., Selten, J.P. (2003). Sex differences in the risk of schizophrenia. Arch Gen Psychiatry. 60: 565571. DOI PMid:12796219 
Drake, R.J., Haley, C.J., Akhtar, S. (2000). Causes and consequences of duration of untreated psychosis in schizophrenia. British Journal of Psychiatry. 177: 511-515. DOI PMid:11102325

Carpiniello, B., Pinna, F., Tusconi, M., Zaccheddu, E., Fatteri, F. (2012). Gender Differences in Remission and Recovery of Schizophrenic and Schizoaffective Patients: Preliminary Results of a Prospective Cohort Study. Schizophrenia Research and Treatment. In Press DOI

Ganev, K., Onchev, G., Ivanov, P. (1998). A16-year follow-up study of schizophrenia and related disorders in Sofia, Bulgaria. Acta Psychiatrica Scandinavica. 98: 200-207. DOI PMid:9761406

Harrison, T.R. (2005). Harrison's principles of internal medicine. 16th ed, pp. 2559-2561.

Harrison, G., Hopper, K., Craig, T. (2001). Recovery from psychotic illness: a 15- and 25-year international follow-up study. British Journal of Psychiatry. 178: 506-517. DOI PMid:11388966

Haro, J.M., Novick, D., Bertsch, J., Karagianis, J., Dossenbach, M., Jones, P.B. (2011). Cross-national clinical and functional remission rates: Worldwide Schizophrenia Outpatient Health Outcomes (W-SOHO) study. The British Journal of Psychiatry. 199: 194-201. DOI PMid:21881098

Isaac, M., Chand, P., Murthy, P. (2007). Schizophrenia outcome measures in the wider international community. British Journal of Psychiatry. 191(suppl.50): 71-77. DOI

Isaac, M., Kapur, R.L., Chandrasekhar, C.R. (1981). Management of schizophrenia patients in the community. An experimental report. Indian Journal of Psychological Medicine. 4: 23-27.

Kurihara, T., Kato, M., Reverger, R. (2000). Outcome of schizophrenia in a non-industrialized society: comparative study between Bali and Tokyo. Acta Psychiatrica Scandinavica. 101: 148-152. DOI PMid:10706016

Kurihara, T., Kato, M., Reverger, R. (2005). Eleven-year clinical outcome of schizophrenia in Bali. Acta Psychiatrica Scandinavica. 112: 456-462. DOI PMid:16279875

Lacro, J.P., Dunn, L.B., Dolder, C.R., Leckband, S.G., Jeste, D.V. (2002). Prevalence of and risk factors for medication nonadherence in patients with schizophrenia: a comprehensive review of recent literature. The Journal of Clinical Psychiatry. 63(10): 892-909. DOI PMid:12416599

Large, M., Farooq, S., Nielssen, O., Slade, T. (2008). Relationship between gross domestic product and duration of untreated psychosis in low and middle-income countries. The British Journal of Psychiatry. 193: 272-278. DOI PMid:18827287
Marwaha, S., Johnson, S. (2004). Schizophrenia and employment. A review. Social Psychiatry and Psychiatric Epidemiology. 39: 337-349. DOI PMid:15133589

Mueser, K.T., Salyers, M.P., Mueser, P.R. (2001). A prospective analysis of work in schizophrenia. Schizophrenia Bulletin. 27: 281-296. DOI PMid:11354595

Nanko, S., Moridaria, J. (1993). Reproductive rates in schizophrenic outpatients. Acta Psychiatrica Scandinavica. 87: 400-404. DOI PMid:8356891

Padmavathi, R., Rajkumar, S., Srinivasan, T.N. (1998). Schizophrenic patients who were never treated a study in an Indian urban community. Psychological Medicine. 28: 1113-1117. DOI PMid:9794018

Pai, S., Kapur, R.L. (1982). Impact of treatment intervention on the relationship between dimensions of clinical psychopathology, social dysfunction and burden on the family of psychiatric patients. Psychological Medicine. 12: 651-658. DOI

Patel, V., Cohen, A., Thara, R. (2006). Is the outcome of schizophrenia really better in developing countries? Revista Brasileira de Psiquiatria. 28: 149-152. DOI PMid:16810400

Srinivasan, T.N., Thara, R. (1997). How do men with schizophrenia fare at work? A follow up study from India. Schizophrenia Research. 25: 149-154. DOI

Srinivasan, L., Tirupati, S. (2005). Relationship between cognition and work functioning among patients with schizophrenia in an urban area of India. Psychiatric Services. 56:1423-1428. DOI PMid:16282262

Srinivasan, T.N., Thara, R. (2001). Beliefs about causation of schizophrenia: do Indian families believe in supernatural causes? Social Psychiatry and Psychiatric Epidemiology. 36: 134-140. DOI PMid:11465785

Thara, R., Eaton, W.W. (1996). Outcome of schizophrenia: the Madras longitudinal study. Australian and New Zealand Journal of Psychiatry. 30: 516-522. DOI PMid:8887703

Thara, R., Kamath, S., Kumar, S. (2003a). Women with schizophrenia and broken marriages - doubly disadvantaged? I. Patient perspective. International Journal of Social Psychiatry. 49: 225-232. DOI PMid:14626365

Thara, R. (2004). Twenty-year course of schizophrenia: the Madras Longitudinal Study. Canadian Journal of Psychiatry. 49: 564-569. PMid:15453106

Tsoi, W.F., Wong, K.E. (1991). A15-year follow-up study of Chinese schizophrenic patients. Acta Psychiatrcia Scandinavica. 84: 217-220. DOI PMid:1950620 